2 Davies, D P, Archives of Disease in Childhood, 1977, 52, 296.

3 Jivani, S K M, Archives of Disease in Childhood, 1978, 53, 69.

4 American Academy of Pediatrics, Committee on Nutrition, Pediatrics, 1977, 59, 460 .

${ }^{5}$ Robson, J R K, Pediatric Clinics of North America, 1977, 24, 189.

${ }^{6}$ Robson, J R K, et al, Pediatrics, 1974, 53, 326.

7 Shull, M W, et al, Pediatrics, 1977, 60, 410.

${ }^{8}$ Lloyd, G E R, ed, Hippocratic Writings, p 72. Harmondsworth, Penguin, 1978.

\section{No-fault liability}

Five years after its appointment, Lord Pearson's Royal Commission on Civil Liability and Compensation for Personal Injury ${ }^{1}$ has submitted an encyclopaedic, but disappointingly unimaginative, report for the Queen's consideration. Naturally there is much to be welcomed, including the recommended $f^{4}$-per-week tax-free benefit to be paid (in addition to child benefit) to all severely handicapped children from the age of 2 years, regardless of the cause of their disability. The commission has also dealt with the question of vaccine damage. Disregarding their fears that the public might see in a special scheme of compensation an admission that there were real dangers in vaccination, they suggest that the Government or the local authority concerned should be strictly liable to children and adults caused injury by vaccination programmes.

It would be churlish not to welcome the recommendation of a compensation scheme, irrespective of proof of fault, for injuries suffered in road accidents. In Saskatchewan such a scheme has existed since 1946, but in Europe Sweden is the only country at present paying such compensation. Lord Pearson suggests that the British scheme should be run by the Department of Health and Social Security on the model of the present Industrial Injuries benefit, though it would extend to non-earners. The necessary money to meet the estimated $£ 28 \mathrm{~m}$ extra cost after five years (rising to $£ 54 \mathrm{~m}$ on maturity) would come from a penny-a-gallon levy on petrol. Against this extra cost must be set a saving of $£ 40 \mathrm{~m}$ on the present compensation payable on proof of fault.

Recent studies cited by the commission show that only $25 \%$ of those injured on the roads and $10.5 \%$ of those injured at work obtain compensation based on proof of fault ("tort compensation"). Overall, only $6.5 \%$ of all people injured receive tort compensation, and for children under 15 the figure is a dismaying $1 \%$. The commission's essentially conservative bent (there were a total of six lawyer members) is shown by their advice that tort liability should be retained to supplement the no-fault road-accident compensation scheme. At the same time they have resisted proposals that the burden of proof should be reversed, so that, for example, a motorist involved in an accident, or an employer in the case of industrial injury, should have to show that no negligence by them caused the injury if they were to escape the payment of compensation.

As the figures for compensation show, the common law action for damages based on proof of negligence is a "forensic lottery," originating in the common law's sentiment that the wrongdoer must pay for his offence. Today this seems mediaeval to the point of barbarism: compensation turns on such fortuitous circumstances as the nature of the accident, the presence of witnesses, and the means of the defendant. In April 1974 New Zealand tackled the common law's deficiencies root and branch. All rights to claim damages for accidental injuries were abolished and in substitution the
Accident Compensation Commission was set up to pay compensation to all accident victims through a State-run insurance scheme. The awards made are periodically reviewed for inflation, and include lump sums for loss of bodily function and periodical payments that are related to earnings. The latter have a fixed ceiling, so that high earners require extra insurance, especially as their remedy in tort no longer exists.

Lord Pearson's caution is most plainly shown by the commission's belief that the New Zealand scheme has not been working long enough for its effectiveness or desirability to be assessed. The commission has therefore recommended that no-fault compensation should be confined to road accidents. Unlike in New Zealand, victims of road accidents will not be prevented from suing in tort, but will have to give credit for any no-fault compensation. Though the commission sees tort as the "junior partner" to social security, tort will clearly remain the primary remedy for all major injuries, including industrial injuries, provided that fault can be established. As regards tort and industrial injuries, Professor Richard Schilling dissents from the remainder of the commission. He believes (following the view of the Robens Committee) that litigation by the employee against the employer is counter-productive to good industrial relations and safety at work. A further disadvantage is that action in tort with all its delays tends to militate against the victim's speedy recovery.

The commission's recommendations in relation to injuries caused by medical treatment are particularly disappointing. Since negligence in medical treatment results in injury to the patient, it is not unreasonable to treat negligence by doctors or other health workers differently from that of other professional men. In recent years numerous plaintiffs who have suffered serious harm as a result of medical treatment have failed to secure compensation. Two particularly striking examples were reported in the $B M F$ in 1975 : in the first case ${ }^{2}$ an axillary aortogram resulted in serious neurological complications, but the judge dismissed the action because he held that the proximity of the nerves of the brachial plexus to the point of puncture in the axilla meant there was always a danger of injury to the nerves of the arm however skilfully the operation was performed. In the second case $^{3}$ damages were refused to a 57-year-old man who had had sclerosant fluid injected into an artery while undergoing Fegan's compression sclerotherapy behind the medial malleolus. At the trial evidence was called on either side (which must have been of little consolation to the plaintiff) about whether the medial malleolus was a safe site for injection. A substantial body of opinion supported the defendant, and the judge therefore rightly dismissed the claim. As our legal correspondent said at the time, the judgment "supported the argument that a technique's possible hazards or side effects can, if infrequent enough, be justified by the technique's benefits, if great enough."

But what is to be done for the victim of an infrequent hazard? We must not forget that the repercussions of a successful action are quite different for a defendant who is a doctor than for one who is a car driver, since the judge can award damages only by damning the reputation of the doctor simultaneously. The Royal Commission shows no sign of awareness of this judicial dilemma and for reasons that are far from clearly expressed they have shied away from any no-fault scheme for compensation for medical accidents as exists in New Zealand and Sweden. Primarily they seem to have been concerned about proof of causation, but difficult questions of causation confront the courts every day and equal 
doubts will exist about the causation of antenatal injuries and vaccination injuries, for which the commission supports a cause of action. The question is one of drawing a line, and the fact that it may not be easy in some cases is no ground for refusing a remedy in all cases. In New Zealand the problem has been dealt with by placing a restrictive interpretation on the words "medical misadventure" so that compensation does not result every time medical treatment fails: no compensation was paid when an embolus developed in a leg operation, on the grounds that such an operation has always entailed the risk of blood clotting. In Sweden, too, the system seems to work satisfactorily, actually protecting doctors from the likelihood of being sued in tort and giving compensation to many more than could ever have recovered it previously.

Only in relation to medical experiments does the commission make an exception. Here they cite an instance where the Medical Research Council made an ex gratia payment to a volunteer who developed a neurological lesion shortly after receiving live attenuated influenza vaccine. Lord Pearson recommends that there should be strict liability for any volunteer in medical research who suffers severe damage as a result. Ironically, the commission ignores the point that this would not have availed the volunteer in the MRC trial, since in his case a causal connection could be neither proved nor disproved.

The commission's voluminous recommendations deserve the same painstaking study as brought them into being. In particular, the medical profession and the pharmaceutical industry will have to think deeply about the recommended strict liability for dangerous drugs. The long shadow cast by practolol, which continued to be prescribed after being withdrawn by ICI, has led to the commission's recommending that proof that the manufacturer withdrew or tried to withdraw the product should not be a defence. Doubts may be raised about the justice of that, just as questions may be asked about the long-term wisdom of not permitting a defence of development risk to pharmaceutical companies, especially since the commission proposes no ceiling on the producer's liability. Nor does the commission think that it should be a defence that the Committee on Safety of Medicines sanctioned the sale of the drug. There is much to be discussed before the commission's recommendations reach the stage of legislation before Parliament.

${ }^{1}$ Royal Commission on Civil Liability and Compensation for Personal Injury (chairman Lord Pearson). London, HMSO, 1978, cmnd 7054-1, 2 , and 3.

${ }^{2}$ British Medical fournal, 1975, 1, 635.

3 British Medical fournal, 1975, 4, 714

${ }^{4}$ Cooper, J, New England Fournal of Medicine, 1976, 296, 1268.

\section{Whooping-cough vaccines}

Two important points about whooping-cough vaccines are clearly made in an article by Dr A H Griffith on page 809 of this issue. Firstly, in the past these have differed appreciably one from another in respect of their toxic effects, as judged by tests in mice; their content of agglutinogens; their potency; and their protective efficacy in children. Their liability to produce adverse reactions was probably equally variable. These points, though well established and known to experts, seem not to be generally appreciated and have certainly not been prominent in the public discussions of adverse reactions after whooping-cough vaccination. Secondly, Dr Griffith's study shows that any manufacturer who accepts his obligation to collect, record, and consider the incidence of reactions to his vaccine faces a frustrating and indeed nearly impossible task.

These conclusions emerged from the efforts made by the Wellcome Foundation to ascertain the incidence of severe reactions after administration of its whooping-cough vaccines. The Wellcome product, it is important to emphasise, was shown by the five-year survey of the Public Health Laboratory Service $^{1}$ to be superior in protective efficacy to another British vaccine. During the past 25 years the Wellcome vaccine has invariably been produced on solid medium containing charcoal, a procedure intended to absorb the bacterial toxins from the surface cultures. This method of production is more troublesome and more expensive than that of culture in fluid medium in deep tanks, which was used-at least for a timeby certain other manufacturers of whooping-cough vaccines. Although fluid-culture vaccines can be and are made to meet all the required specifications of the appropriate licensing authorities, Wellcome have taken the view that such vaccines tend to be more toxic in some animal tests than are solidculture vaccines and that their potency (in terms of standard international units) may have to be reduced to ensure that they pass the toxicity tests.

There was good reason, therefore, for Wellcome to try to ascertain whether their whooping-cough vaccines caused fewer adverse reactions as well as conferring significantly better protection on immunised children. Given the whole picture presented in the public campaigns against whoopingcough vaccines, the details described and assessed in $\mathrm{Dr}$ Griffith's paper certainly suggest very strongly not only that deaths and persistent neurological damage were uncommon with the Wellcome vaccine but also that such reactions are difficult to attribute with certainty to the immunisation. After all the relevant information had been collected from the authors of published papers, from hospital records, and from the Committee on Safety of Medicines there seemed to have been only six deaths between 1964 and mid-1977 after administration of Wellcome vaccine. At least three of these were not the result of the vaccine. In addition, five or possibly six cases of persistent neurological damage were recorded after but not necessarily due to administration of the vaccine. Alternative causes were apparent in some of the cases.

Beyond question, therefore, despite some missing pieces of relevant but unobtainable information, there is a prima facie case for investigating whether or not the Wellcome vaccine caused fewer reactions than the others in use at the same time or whether equally detailed investigations of other vaccines would have shown comparably low rates of serious adverse reactions. We need to know whether vaccines made in different ways vary in their toxicity as well as in the protection they provide. Surely it is not beyond our resources and ingenuity to devise a way in which the full details of every protective immunisation are accurately recorded and stored in a national computer. Only in this way could we deal with several important problems at present complicating the immunisation campaign. This campaign is one of our most beneficial efforts in preventive medicine, but it is now frustrated and bedevilled by allegations that cannot be properly assessed by reason of incomplete information.

Whooping-cough vaccines are not our only concern. Some years ago there was an influenza vaccine with an oil adjuvant which had to be withdrawn because it might induce neoplastic changes. How could an effective follow-up to assess such a long-term anxiety be effective without full details of the 